\title{
AN EXPERIMENTAL STUDY OF AVIAN BERIBERI.*
}

\author{
By G. Marshall Findlay, O.B.E., M.D., Carnegie Research Scholar. \\ From the Royal College of Physicians' Laboratory, Edinburgh.
}

The following research was undertaken in order to investigate the rôle of vitamin $\mathrm{B}$ in normal metabolism. The feeding experiments were carried out at Port Said, Egypt, during the spring and summer of 1919. It was not, however, until my return to this country that, thanks to a grant from the Carnegie Research Trust, I was able to examine the histological material previously obtained. I desire to express my sincere thanks both to the Carnegie Trust and the Royal College of Physicians, Edinburgh, for their assistance.

Forty-three fowls and forty-one pigeons were employed in these experiments. Of these birds, twelve were found to be infected at death. One fowl suffered from coccidiosis of the liver; one fowl and six pigeons were infected with $B$. coli, two fowls and two pigeons with B. pyocyaneus. It should be noted that the degree of domestication in Egyptian fowls is not as great as in fowls in this country, and in addition they are smaller in size. Of the fowls, twelve were fed on mixed grain as controls, fifteen on an exclusive diet of polished rice70 grms. per diem-while twelve were given water only, in order to compare the effects of inanition. Of the pigeons, fifteen were fed on polished rice, while twelve were used as controls. Six pigeons were given a ration of oats and maize-10 grms. of each grain on alternate days, with one-tenth of the body-weight of yeast every third day.

\section{Clinical Observations.}

(A.) Avian Beriberi.

I. Incubation Period.-In the present series of experiments the average period elapsing before the onset of symptoms was 31.5 days in uninfected fowls, the shortest period being 18 days, the longest 74 days. In the case of the pigeons, the average was $27 \cdot 2$ days, the shortest 21 days, the longest 43 days. Several factors influence the incubation period, the principal being age, sex,

* Part of a thesis presented for the degree of Doctor of Medicine in the University of Edinburgh, for which a gold medal was awarded. (Received November 30, 1920.) 
diet prior to the experiment, exertion during the experiment, quantity of rice eaten during the experiment, bacterial or other infection.

1. Age.-In the present instance the fowls were all about three-quarters grown, while only young adult pigeons were employed. The question of age did not, therefore, arise in these experiments.

2. Sex.-When artificial feeding is not adopted the incubation period is slightly shorter in the male, possibly owing to its more voracious appetite.

3. Diet Prior to the Experiment.-There is at present very little information as to whether the body can store up a large supply of vitamin B. A few experiments were, therefore, carried out with pigeons. Twelve birds were employed, divided into four groups :-

Group $A$ was fed for ten days on one-twentieth the body-weight of polished rice plus one-thousandth the body-weight of yeast.

Group B was fed for ten days on one-twentieth the body-weight of polished rice plus one-hundredth the body-weight of yeast.

Group $\mathrm{C}$ was fed for ten days on one-twentieth the body-weight of polished rice plus one-tenth the body-weight of yeast.

Group D was fed for ten days on one-twentieth the body-weight of polished rice plus one-fifth the body-weight of yeast.

After ten days on the above diet the birds were placed on an ad libitum diet of polished rice and the incubation period noted.

The average incubation period for Group A was $22{ }^{\circ}$ days.

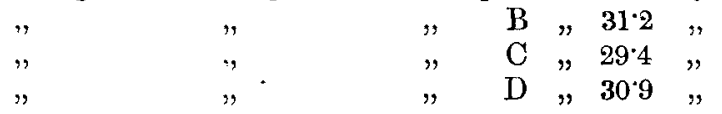

With the smallest quantity of yeast there was little or no protection. Since Group B showed a definite though slight prolongation of the incubation period, while in Groups $\mathrm{C}$ and $\mathrm{D}$ the incubation period was not prolonged, it is probable that the tissues are only able to store up a limited amount of vitamin $B$.

4. Exertion during the Experiment.-The effect of exertion in hastening the onset of beriberi in man has often been noted. The following experiment illustrates the same effect in the case of fowls:-Three fowls were kept on the move for one hour a day. The incubation period in these three cases was sixteen, nineteen, and twenty-one days respectively, while it is noteworthy that in every case the bird died within thirty-six hours of the onset of symptoms.

5. The Quantity of Rice Eaten during the Experiment.-When artificial feeding is not adopted it is found that in the majority of cases the appetite decreases after the first few days, and by the time paralytic symptoms appear the daily ration has been voluntarily reduced to 2 or 3 grms. Maurer (1907 1) definitely showed that the greater the amount of rice consumed the shorter the incubation period. Possibly the energy expended on digestion and metabolism is a factor in hastening the onset of beriberi.

6. Bacterial or other Infections.-These undoubtedly play some part in hastening the onset of beriberi. Thus the average incubation period for infected fowls was 25.2 days, excluding the bird suffering from coccidiosis, which developed symptoms in three and a half days. In pigeons the average period was $20^{\circ} 4$ days. 
II. The Onset and Course of the Disease.-The main symptoms of the disease may be described in brief. During the period of incubation there is almost always some diarrhoea, while the stools are light in colour. The actual onset of symptoms is as a rule gradual. The feathers are ruffled and the bird ceases to nreen itself. For the most part it sits with the head sunk between its shoulders, while if it walks it keeps the tibio-tarso-metatarsal joint partially flexed owing to commencing paralysis of the extensor muscles of the leg. From the appearance of the first symptoms to the time of death is usually from two to three days, though one fowl lived for eight days after the initial symptoms, while another died after six hours. Prior to death the bird usually passes into a semicomatose condition, though occasionally death occurs without warning, or, in the case of pigeons, during a convulsive seizure.

III. Nervous Symptoms-(a) Paralysis.-Paralytic symptoms first appear in the flexor muscles of the toes. Thence they spread upwards, involving the extensors of the legs and the wing muscles. In pigeons, however, "wing drop" is rare. Later the muscles of the neck are paralysed, more particularly the anterior muscles, with the result that head retraction is a marked symptom. In three pigeons emprosthotonos was noted. At a late stage dysphagia occurs.

(b) Sensory Changes.-So far as can be judged there is an impairment of the sensations of touch, temperature, and pain on the legs.

(c) Cerebellar Disturbances.--Involvement of the cerebellum only occurred in one fowl, but it was noted in all the pigeons except four. The cerebellar involvement is characterised by convulsive attacks of a periodic character. The attacks can be induced by any sudden stimulation. In minor attacks the bird turns slowly round and round, while in major attacks it tends to turn somersaults backwards.

IV. Temperature Changes.-In healthy birds the diurnal range of temperature taken in the cloaca is from $105^{\circ} \mathrm{F}$. to $109^{\circ} \mathrm{F}$. On a diet lacking in vitamin $\mathrm{B}$, the average daily temperature gradually falls to $99^{\circ}, 98^{\circ}$, or even $96^{\circ} \mathrm{F}$. If given a curative dose of vitamin $\mathrm{B}$, however, the temperature rises again to $103^{\circ} \mathrm{F}$. to $105^{\circ} \mathrm{F}$., as the muscular paralysis disappears.

V. Changes in the Cardiac and Respiratory Functions.-In birds suffering from beriberi there is a progressive slowing of the respiratory rate, while in the later stage of the disease symptoms suggestive of air-hunger are not uncommon. The administration of a sufficient dose of yeast or other substance containing vitamin $B$ causes the respiratory rate to return rapidly to normal.

As a rule, in beriberic birds there is a marked acceleration of the heart's action, less commonly a slowing. Here again the administration of vitamin B causes a return to the normal.

VI. Edema of the lower extremities was not noticeable during life in any of the fowls or pigeons used in the experiments.

VII. Changes in Body.weight.-When fed on an exclusive diet of polished rice both fowls and pigeons lose weight. Fowls lost 25.6 per cent. of their bodyweight at the beginning of the experiment, or 1.2 per cent. per diem. Pigeons on the other hand lost $29^{\circ} 0$ per cent., or 2.5 per cent. per diem. In many cases there is a rapid fall in weight shortly before death. In some instances this fall begins before the appearance of nervous phenomena, in others after.

\section{(B.) Acute and Chronic Inanition in Birds.}

In the case of fowls given water only, death took place in an average period of $11^{*} 6$ days, the shortest period being $3^{*} 5$, the longest 17 days.

JOURN. OF PATH. --voL. XXIv. 
Clinically no signs of involvement of the nervous system were noticeable; progressive asthenia was the main feature. The respirations were slowed, but not to the same extent as in beriberic birds, and though a fall in temperature

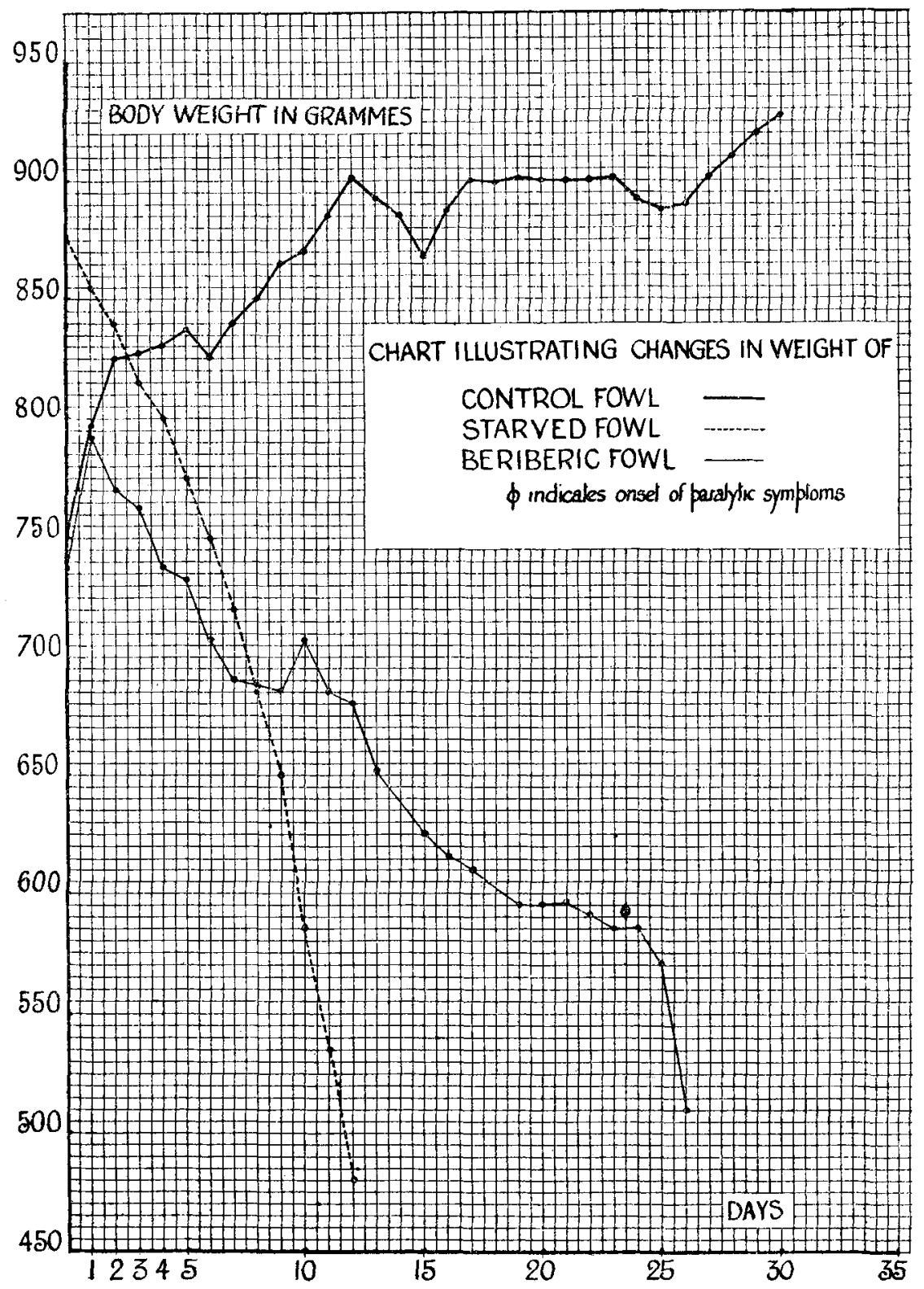

occurred it never fell below $99^{\circ} \mathrm{F}$. The loss of weight amounted to $38^{\circ} 7$ per cent. of the weight at the beginning of the experiment, or 6.5 per cent. per diem.

Of the pigeons fed on oats, maize, and yeast, two survived the full term of the experiment and were killed on the thirty-fifth day, while four others died 
in an average period of twenty-seven days. Here again there were no paralytic symptoms though the respiratory rate was slowed and the temperature lowered as in fowls dying from acute inanition.

\section{Histological Obsertations.}

On post-mortem examination of a bird that has died from avian beriberi, the most striking feature is the extreme degree of atrophy of all the tissues. As the result of weighing the organs in beriberic birds and in those dying of inanition, it has been possible to estimate the relative degree of atrophy in the two conditions. From an examination of Tables I.-III., it is noticeable that both in beriberi and inanition the adrenals hypertrophy, the pituitary appears to undergo little or no change, and the remainder of the other organs atrophy.

In describing the various organs, the systems will be considered in the following order:-(1) Nervous System; (2) Endocrine Organs; (3) Genito-Urinary System; (4) Circulatory System; (5) Alimentary System; (6) Museular and Osseous Systems.

Table I.--Pigeons.

Showing average weights of organs of control pigeons, of those fed on polished rice and of pigeons subjected to chronic inanition, but with Water Soluble B factor present in the diet. Weight calculated in terms of original body-weight.

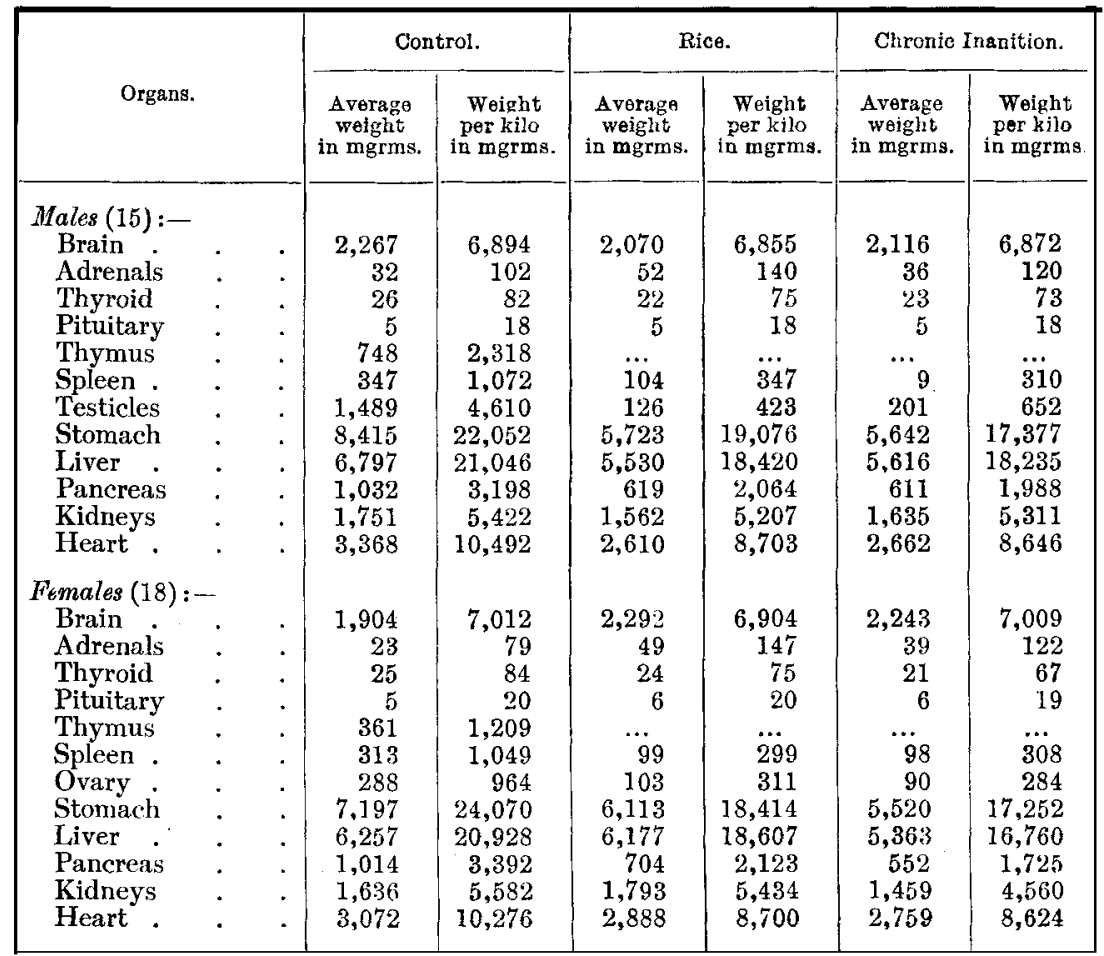


TABLE II.-Fowls.

Showing average weights of organs of control fowls, of those fed on polished rice and of those subjected to acute inanition. Weight calculated in terms of original body-weight.

\begin{tabular}{|c|c|c|c|c|c|c|c|c|}
\hline \multirow[b]{2}{*}{ Organs. } & & & \multicolumn{2}{|c|}{ Control. } & \multicolumn{2}{|c|}{ Rice. } & \multicolumn{2}{|c|}{ Acute Inanition. } \\
\hline & & & $\begin{array}{c}\text { Average } \\
\text { weight } \\
\text { in mgrms. }\end{array}$ & $\begin{array}{c}\text { Weight } \\
\text { per kilo } \\
\text { in mgrms. }\end{array}$ & $\begin{array}{c}\text { Average } \\
\text { weight } \\
\text { in mgrms. }\end{array}$ & $\begin{array}{c}\text { Weight } \\
\text { per kilo } \\
\text { in mgrms. }\end{array}$ & $\begin{array}{c}\text { Average } \\
\text { weight } \\
\text { in mgrms. }\end{array}$ & $\begin{array}{c}\text { Weight } \\
\text { per kilo } \\
\text { in mgrms. }\end{array}$ \\
\hline \multicolumn{9}{|l|}{ Males (23):- } \\
\hline Brain & - & - & 2,632 & 4,785 & 3,146 & 4,528 & 3,404 & 4,620 \\
\hline Adrenals & . & . & 113 & 206 & 218 & 315 & 169 & 230 \\
\hline Thyroid & - & - & 43 & 78 & 515 & 72 & 50 & 69 \\
\hline Pituitary & . & - & 9 & 17 & 11 & 16 & 12 & 16 \\
\hline Thymus & & $\cdot$ & 1,624 & 2,952 & $\cdots$ & $\ldots$ & ‥ & $\ldots$ \\
\hline Spleen . & - & . & 1,499 & 2,725 & 662 & 952 & 795 & 1,078 \\
\hline Testicles & 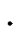 & . & 1,050 & 1,909 & 510 & 734 & 558 & 757 \\
\hline Stomach & • & . & 13,170 & 23,945 & 13,512 & 19,396 & 14,118 & 19,156 \\
\hline Liver . & . & . & 19,092 & 34,712 & 21,077 & 30,547 & 22,001 & 29,853 \\
\hline Pancreas & - & - & 1,345 & 2,445 & 1,218 & 1,761 & 1,235 & 1,743 \\
\hline Kidneys & - & . & 4,458 & 8,105 & 5,257 & 7,619 & 5,555 & 7,538 \\
\hline Heart. & - & $\cdot$ & 2,380 & 4,327 & 2,531 & 3,642 & 2,720 & 3,690 \\
\hline \multicolumn{9}{|c|}{ Females (16):- } \\
\hline Brain & 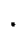 & . & 2,481 & 4,862 & 3,070 & 4,652 & ... & $\cdots$ \\
\hline Adrenals & . & . & 99 & 187 & 209 & 318 & .. & $\ldots$ \\
\hline Thyroid & • & . & 41 & 78 & 46 & 71 & ... & $\cdots$ \\
\hline Pituitary & - & . & 9 & 18 & 11 & 18 & $\ldots$ & $\cdots$ \\
\hline Thymus & • & . & 924 & 1,745 & \% & $\ldots$ & $\cdots$ & $\cdots$ \\
\hline Spleen . & • & - & 1,401 & 2,624 & 659 & 998 & $\cdots$ & $\cdots$ \\
\hline Ovary : & * & - & 314 & 592 & 246 & 373 & $\cdots$ & $\because$ \\
\hline Stomach & - & $\cdot$ & 12,626 & 23,822 & 12,578 & 29,058 & $\cdots$ & $\cdots$ \\
\hline Liver . & • & - & 18,285 & 34,500 & 20,037 & 30,360 & $\cdots$ & $\cdots$ \\
\hline Pancreas & • & • & 1,310 & 2,472 & 1,191 & 1,805 & $\cdots$ & $\cdots$ \\
\hline Kidneys & 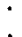 & . & 4,264 & 8,046 & 4,992 & $\begin{array}{l}7,564 \\
3,737\end{array}$ & $\cdots$ & $\cdots$ \\
\hline Heart . & $\theta^{\circ}$ & ${ }^{\circ}$ & 2,276 & 4,290 & $2, \pm 00$ & 3,737 & $\cdots$ & $\cdots$ \\
\hline
\end{tabular}

\section{TABLE III.}

Showing percentage loss in organs of pigeons and fowls fed on polished rice and subjected to inanition; calculated as percentages of weights per kilo of control birds. Sexes combined.

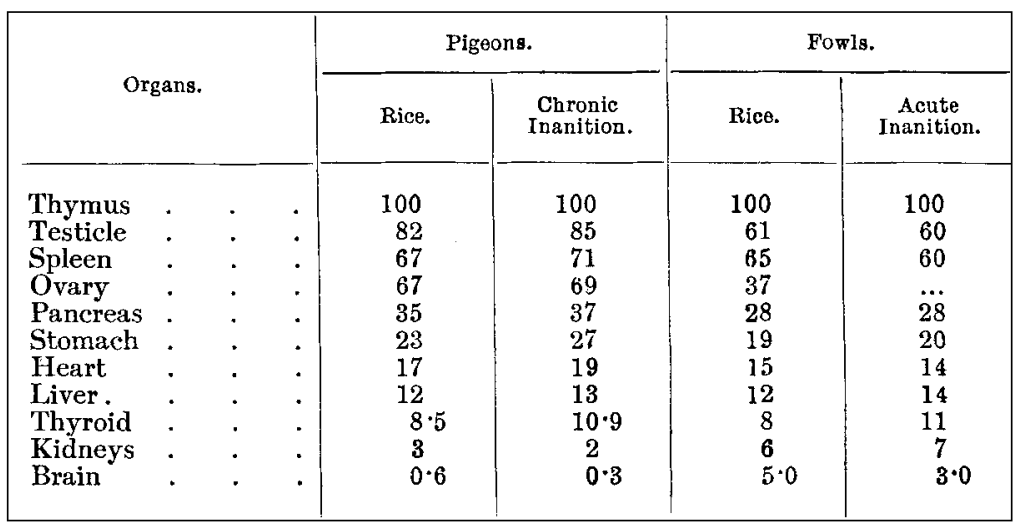


The Nervous System.

Macroscopically the brains of birds dying of beriberi rarely exhibited any abnormality. Occasionally, however, there was slight congestion of the meninges or even of the brain substance itself. At other times the brain substance was of a dead-white colour. In almost every case the brain substance was soft and almost diffluent. No increase was noticeable in the amount of the cerebrospinal fluid. There were no petechial hæmorrhages. The cord appeared normal in all cases. No macroscopical abnormalities were noted in the brains of control birds or of birds subjected to inanition.

In the nervous system of birds fed on polished rice, the following appearances were noted microscopically :-

(1) The Nerve Cells.-The most characteristic change was the almost complete disappearance of the Nissl granules. They were represented by a fine granular mass collected in one part of the cell, usually close to the cone of origin of the axis-cylinder process. The degree of chromatolysis was a little more advanced than that seen in pigeons fatigued by a long flight. On curing a beriberic bird by the administration of vitamin B, the Nissl granules reappeared after the lapse of six to nine hours. In birds dying of inanition only slight evidence of chromatolysis could be found in the nerve cells, nor was it ever so widespread or so marked as in birds fed on polished rice.

(2) Nerve processes. - As a rule in birds dying from beriberi a few fibres are found in the cord and brain staining black by Marchi's method. The distribution of these fibres is entirely capricious and shows no relationship to the bloodvessels or lymphatics. In three fowls and in two pigeons no degenerative changes were noted in the fibres, though the birds all died with typical symptoms of paralysis.

(3) Neuroglia.-No overgrowth of the neuroglial tissue was present.

(4) Blood-vessels. - In a few cases the blood-vessels showed evidence of congestion. In the smaller arteries the muscular fibres were fragmented, while in places there was swelling of the lining endothelium.

(5) The Peripheral Nervous System.-The sciatic nerves were examined in all cases. Degeneration of the myelin sheaths was demonstrated in all the fowls except two, and in all the pigeons except three. The number of fibres affected varied in different birds, and in the two sciatics of the same bird. Changes in the myelin sheath were found in the sciatics of two pigeons with chronic inanition.

The vagi showed degeneration by Marchi's method in all the fowls fed on rice except five, and in all the pigeons except three. None of the birds suffering from inanition showed degenerative changes in the vagi.

(6) The Sympathetic Nervous System.-Changes indicative of degeneration were found in the nerve plexuses of the intestine, while the cells of the ganglia in the adrenals were swollen and vacuolated.

\section{The Endocrine Organs.}

(1) Adrenals.-A definite hypertrophy of the adrenals occurs both in fowls and pigeons fed on polished rice. The degree of hypertrophy is approximately the same in the two species. The hypertrophy is somewhat greater in the female. Hypertrophy, though to a less extent, occurs in fowls and pigeons subjected to inanition. Macroscopically the organs were of a reddish copper hue and were very friable. In some cases a considerable degree of congestion was present. Microscopically no bæmorrhages were found in the adrenals of uninfected birds.

The medullary cells appeared for the most part normal. The chromaffin granules in sections fixed in potassium bichromate or osmic acid vapour appeared

JOURN. OF PATH. - vol. XXIV. 
normal in number. Many of the nuclei were large and vesicular in appearance and showed evidence of a loss of chromatin material. In many adrenals granules of a yellowish-brown pigment wore seattered throughout the tissues. The cortical cells normally contain lipoids, fats, and cholesterol. In beriberi with Scharlach $R$ the whole of this material stains orange, while with Nile blue sulphate the colour is blue or some shade of purple. The presence of cholesterol in small amounts is shown by the Liebermann-Burkhardt test. If a bird suffering from beriberi be given a curative dose of vitamin $B$, the weight of the adrenals decreases, and on examining the cortex microscopically there is found to be a decrease in the amount of lipoid material present. With Nile blue sulphate many of the remaining globules now stain purple or pink. The test for cholesterol, however, is still positive. In addition, whereas in healthy birds only a few cortical cells give the oxydase reaction * with vital methylene blue, now it can be obtained in almost every cell.

(2) Pituitary. - The pituitary undergoes little or no atrophy either in inanition or beriberi. Microscopically no abnormality could be found in the posterior lobe, while in the anterior lobe in a few cells the nuclei stained poorly.

(3) Thyroid.-In birds suffering from beriberi the degree of atrophy is slight. The organ is rather paler than usual. Histologically there is frequently no change to be noted, though sometimes the cells lining the vesicles are degenerated. In birds with inanition the amount of colloid is decreased.

(4) Parathyroids.-These organs appeared normal, but the post-branchial body had undergone slight atrophy.

(5) Thymus. - In birds suffering from beriberi no trace could be found of any thymic tissue; the same is true of birds with inanition even when vitamin $B$ is present in the diet.

(6) Spleen.-In this organ there is marked atrophy both in beriberic birds and in those dying of inanition. The atrophy amounts to nearly two-thirds of the original weight of the organ. Macroscopically in birds fed on polished rice the spleen is of a dark red colour and very friable. Microscopically there is a marked disappearance of lymphoid cells. Congestion is well seen and is associated with the presence of a large amount of yellowish-brown pigment.

\section{The Genito-Urinary System.}

(1) The Genital Organs.-Atrophy takes place in these organs both in birds fed on polished rice and in those suffering from inanition, even when vitamin $B$ is present in the diet. The degree of atrophy of the testicle is greater than that of the ovary.

(a) The testicles of birds dying from beriberi showed definite shrinkage of the tubules. The centre of the tubules was filled with cellular debris in which a few spermatozoa could still be distinguished, though their heads did not take on

* The oxydase reaction is obtained as follows:-Small portions of the adrenals of a freshly-killed bird are placed in a solution of vital methylene blue. The lipoid material takes up the dye. The tissue is then immersed in saline solution and covered with a cover-glass, which is ringed with vaseline. The preparation is now placed in the incubator at $37^{\circ} \mathrm{C}$. and left there for six hours. After this time all the blue colour has disappeared, but on lifting the cover-glass and re-admitting air the colour returns owing to the fact that the granules use up and take up oxygen from the air. Marinesco was the first to point out that under normal circumstances the adrenal cortex does not give the oxydase reaction, since the lipoid content of the cells stains uniformly and not as granules; it is only when some of the lipoid has escaped that small granules of lipoid are seen and these then give the typical oxydase reaction. 
any basic stain. No clear differentiation could be made between spermatogonia, spermatocytes, and syncytial cells, for many of these had lost their lipoid globules. The interstitial cells of Leydig still contained a certain amount of lipoid material, but in many cases the nuclei were swollen and vesicular. Similar changes were seen in birds dying from inanition.

(b) The ovary is small, the vesicles being minute and of uniform size. The membrana granulosa was composed of a single layer of epithelial cells, while the nuclei of some of the interstitial cells showed degenerative changes.

(2) The Kidneys.--As compared with some other organs there is relatively little atrophy. Microscopically there was congestion of the intertubular capillaries, with cloudy swelling of the cells of the convoluted tubules. No fatty degeneration was noted.

\section{The Circulatory System.}

(1) The Heart.-The degree of atrophy was not great. The right heart was frequently dilated, the auricle only being most frequently affected. In two cases in fowls in which both auricle and ventricle were dilated, 10 c.c. and 12 c.c. of fluid were obtained from the pericardial cavity. The heart muscle was soft and pale in colour, and frequently a line of œdema could be seen at the auriculoventricular junction. Microsconically the myocardial cells exhibited cloudy swelling and frequently commencing fragmentation. CEdema of the whole heart muscle was met with in one fowl. In inanition the changes both macroand micro-scopic were very similar. Dilatation of the whole of the right heart was uncommon. Edema at the auriculo-ventricular junction was seen in three fowls and three pigeons dying from inanition.

Hydropericardium. - The amount of fluid varied from one drop to 12 c.c. in fowls, and from one drop to 4 c.c. in pigeons. Hydropericardium was present in

4 out of 15 cases or 26 per cent. of fowls with beriberi;

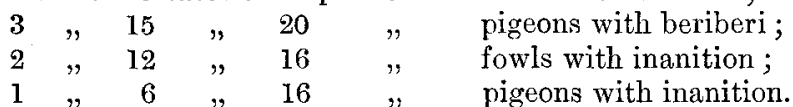

No relationship could be found between the size of the adrenals and the degree of hydropericardium.

(2) The Blood-vessels.-No atheroma was noticeable in the aorta. Microscopically the smaller arteries showed swelling of the intima, while degenerative changes were present in the muscular coat of the media.

\section{The Alimentary System.}

(1) The Esopharys was markedly thinned, owing largely to atrophy of the muscle fibres.

(2) The Crop exhibited similar changes.

(3) The Glandular Stomach showed thinning of its walls with atrophy of the mucosa. Congestion was marked, and the patches of lymphoid tissue had completely disappeared. Active secretion had ceased in the large glands and the lining epithelium showed degenerative changes.

(4) The Muscular Stomach exhibited a considerable degree of atroply. Frequently the mucosa could be easily detached from the subjacent muscular layer. In birds infected with b. pyocyaneus the horny lining layer was stained a bright green.

(5) The Intestines.-In beriberic birds the atrophy of the intestinal wall was so great as to be visible to the naked eye. The duodenum was very congested and frequently ecchymosed. In birds dying from inanition congestion of the 
duodenum was not noted. Microscopically the mucosa and muscular coats had atrophied. The lymphoid tissue had largely disappeared and only a very small quantity was to be found in the cæca.

(6) The Liver.-In beriberic birds the liver was dark red in colour, the substance soft and friable. The gall-bladder as a rule was empty, but in fowls dying from inanition was usually full. Microscopically there was always marked congestion. In a few instances cloudy swelling alone was noted, but in the majority there was very extensive fatty degeneration. Many of the cell nuclei were pale, swollen, and vesicular, and mitotic figures were not seen.

(7) The Pancreas.-There was a considerable degree of atrophy in this organ, while in colour it was dead-white instead of the normal salmon-pink tint. Microscopically the cells lining the alveoli showed cloudy swelling with pale vesicular nuclei. No degenerative changes were noted in the islets of Langerhans.

\section{The Muscular and Osseous Systems.}

In birds fed on polished rice the muscles were soft and rather dark in colour. Microscopically there was loss of cross striation, with considerable atrophy. The bones and joints were examined in a few instances. The bones had evidently taken part in the general atrophy and were lighter than normal.

\section{The Pathogenesis of Beriberi.}

Recent work on nutrition, in addition to proving the existence of vitamins, has shed considerable light on the constitution of an adequate diet, for, provided the vitamins are present, animals can be successfully reared on a diet containing only pure protein, fats, carbohydrates, and salts. Substances such as nucleic acid, the lipoids, cholesterol, creatin must then be synthetised by the body tissues. Although birds develop beriberi with rapidity and regularity when fod on a diet of polished rice, there are certain disadvantages in this experimental procedure, since polished rice is, in addition to its lack of vitamins, deficient in protein, fat, and inorganic salts, while carbohydrates are present in excess.

If, then, we are to arrive at a true conclusion as to the rôle of vitamin $B$ in the vital economy, we must first eliminate as far as possible the pathological changes due to an insufficient supply of salts, proteins, and fats, an excess of carbohydrates and an entire absence of vitamins $A$ and $C$.

Gibson $\left(1913^{2}\right.$ ) found that compensation of the deficient mineral salt content of a diet of polished rice did not prevent, though it appeared to delay slightly, the onset of beriberi in fowls. Nor does an addition of protein to the diet prevent the appearance of the disease, for as Funk $\left(1914^{3}\right)$ has shown, if pigeons are fed on polished rice, with the addition of an excess of the various food-stuffs, the incubation period is considerably shortened by the addition of excess of starch or sugar, slightly shortened by an excess of protein and unaffected by an excess of fat. Little is known in regard to the changes produced by lack of vitamins $\mathrm{A}$ and $\mathrm{C}$ in birds. During the present experiments 1 c.c. of orange juice was given daily to two pigeons fed on polished 
rice without modifying the clinical symptoms or histological findings. In addition none of the experimental birds developed the curious eye condition known as xerophthalmia, which is regarded by many as pathognomonic of a deficiency of vitamin A, nor was there any particular liability to respiratory disease.

It will thus be necessary to discuss the functions of the various organs in health, their impairment in beriberi and their changes in inanition.

1. The Nervous System.-Since the chief clinical symptoms of beriberi are referable to the nervous system, it is only natural that the discovery of Wallerian degeneration in the peripheral nerves by Baelz $\left(1882^{4}\right)$ and Scheube $\left(1884^{5}\right)$ should have led to the general conclusion that beriberi is a form of peripheral neuritis. That this conclusion is untenable is shown by the following facts:-

(1) Degeneration can be demonstrated in the nerve sheaths some days before the onset of paralysis (Vedder and Clark $\left(1912^{6}\right)$ ).

(2) The administration of vitamin $B$ cures the symptoms of paralysis in a few hours in birds, but does not repair the degeneration in the myelin sheath.

(3) Symptoms of beriberic paralysis occur even when no degenerative changes can be found in the myelin sheaths, as shown by M'Carrison $\left(1919^{7}\right)$, and confirmed in the present experiments.

Since, then, the essential lesion is not found in the peripheral nerves, attention is naturally directed to the central nervous system. Now the only changes constantly present in the central nervous system in human and avian beriberi are confined to the cell bodies. In man, chromatolysis and nuclear degeneration are widesprear, while in birds the process is not so far advanced, and chromatolysis only is the main feature. As has been pointed out above, the administration of vitamin $\mathrm{B}$ to a bird with beriberic paralysis is promptly followed by a disappearance of the paralysis, while at the same time there is a reappearance of the Nissl granules in the nerve cells. There is, therefore, presumptive evidence that the paralysis is in some way connected with the disappearance of the Nissl granules. These granules are usually regarded as being composed of nucleo-protein. Without entering into the question whether Nissl granules exist as such in the living nerve cell, it may be taken for granted that, since the metabolism of the neurone is presided over by the nucleus, the appearance or nonappearance of the Nissl granules in a fixed and stained cell is indicative of the activity of the nucleus of that cell during life. Marked chromatolysis is then a sign of nuclear inefficiency-nuclear starvation -and as a result the paralysis of beriberi is in some way associated with nuclear starvation.

2. The Endocrine Organs-(a) The Adrenals.-One of the most interesting changes in avian beriberi is the constant hypertrophy of the adrenals. M'Carrison (1919 ${ }^{7}$ ) regarded this hypertrophy as solely due 
to an increase in the medullary tissue, but as certain of his own figures clearly show, the cortical cells constitute a much greater proportion of the section in diseased than in healthy birds.

If, however, a bird with beriberi is given a curative dose of vitamin $\mathrm{B}$ and then killed some nine hours afterwards, a striking change is noted in the cortical cells. The lipoid content has decreased to a remarkable degree, and is now less than that normally present in controls.

When vitamin $\mathrm{B}$ is administered to a bird with beriberic paralysis, there are thus three changes occurring with remarkable rapidity:-

(1) The disappearance of the paralysis;

(2) The reappearance of the Nissl granules;

(3) The reduction in the lipoid content of the adrenal cortex.

These changes would appear to be intirnately related with one another and with the administration of vitamin B. To explain this correlation, it is necessary to inquire into the function of the adrenal cortex. In the main the adrenal cortex appears to be associated with two sets of organs-the nervous system and the genital system. That the cortical lipoid probably serves as a reservoir of food, both for the developing and adult nervous system, is shown by the fact that there is a close correspondence in size between the brain and the adrenal cortex in the animal series, while in anencephalous monsters the cortex is markedly diminished.

Quite recently, also, Prior and Jones $\left(1920^{\circ}\right)$ have pointed out that in epileptics one finds in a high percentage of cases degenerative changes in the cortex. Furthermore, the adrenal cortex regulates the supply of lipoid to the reproductive organs, for, as Mott $\left(1919^{9}\right)$ has pointed out, the phosphorised lipoids of the adrenal are essential for the maintenance of spermatogenesis. It is therefore probable that phosphorised lipoids are necessary for the synthesis of nucleic acid. This assumption is supported by the following facts:-

(1) During the breeding season the salmon takes little or no food. At the same time its genital organs increase onormously in size, and it produces millions of spermatozoa, the heads of which, as Kossel $\left(1906^{10}\right)$ showed, are composed of nucleic acid and a protamine "salmin." The protamine comes from the muscles, while during the breeding season the blood contains an excess of phosphorised lipoid, which is presum. ably used in producing the heads of the countless spermatozoa.

(2) In the fresh egg neither nucleo-proteins nor pentoses are present, while purin bases are only to be found in small traces. Durinc development, however, these substances increase in amount, having beer formed from the food material present in the egg, i.e., protein anc phosphorised lipoid. In the fresh egg, as Plimmer and Scott (1909 ${ }^{11}$ have shown, 65 per cent. of the total phosphorus is present in the form of lipoid, while in the chick only 20 per cent. is so combined. 
It thus seems probable that the adrenal cortex forms a depôt for phosphorised lipoid, which is then passed on to the central nervous system and genital organs to assist in forming nucleic acid. It may be urged that the adrenal cortex hypertrophies in order to protect the myelin in the medullary sheaths of the nerves. It is quite impossible, however, to correlate the degree of hypertrophy in the adrenals with the extent of the degeneration in the myelin sheaths.

To summarise, then, the changes in the nerve cells in beriberi are indicative of nuclear starvation. Yet in beriberi we find stored in excess in the adrenals one of the substances which are essential for the formation of nucleic acid. When vitamin $B$ is administered there is on the one hand a removal of lipoid from the adrenal cortex, and on the other hand an end to nuclear starvation. Provisionally, then, we may formulate the hypothesis that vitamin $B$ is essential for the formation of nucleic acid. When the tissue content of vitamin $B$ falls below a certain level the phosphorised lipoid, instead of passing on to the central nervous system, is immobilised in the adrenal cortex: the central nervous system begins to run short of nuclear material, and a functional paralysis occurs. If the nuclear shortage becomes very acute, the essential nerve centres in the medulla are at length affected and death ensues, but if vitamin $B$ is given in time the lipoid of the adrenal cortex is liberated, the nuclear starvation of the central nervous system disappears, and the paralytic bird is restored to health with dramatic rapidity.

If the hypothesis which we have suggested be correct, several facts can be viewed in a new light. It becomes apparent why muscular activity, by using up nuclear material in the central nervous system, as evidenced by chromatolysis, causes a shortening of the incubation period of beriberi; why, in fact, any condition such as growth, entailing an increased demand for nuclear material, should rapidly use up the available supply of vitamin $B$ factor, while starvation, in which nuclear activity is reduced to a minimum, is not accompanied by symptoms of beriberi.

The results of total extirpation of the adrenals are also of fresh interest in this connection. Abelous and Langlois (1892 $\left.{ }^{12}\right)$ noted the effects of extirpation of the adrenais in frogs. The symptoms, beginning twenty-four to thirty-six hours after the operation, consisted of a progressive paralysis, first in the hind legs, then passing on to the front limbs until the animal became completely inert. The respirations were slowed, asthenia was pronounced and the animal died. The more active the chemical processes in the animal, e.g., in summer frogs as compared with winter frogs, the more quickly did death supervene. Gourfein $\left(1895^{13}\right)$ obtained similar results with pigeons, while Donetti $\left(1897^{14}\right)$ found changes in the nerve cells of guinea-pigs and rabbits, more especially in the medulla, the nuclei being vesicular, excentric, or even totally absent. The similarity of these findings to 
the clinical symptoms and histological changes in the central nervous system in beriberi is rather remarkable.

It is well known that patients with Addison's disease are easily fatigued. In many cases of Addison's disease the adrenal cortex and medulla are both affected; the cause of the fatigue may thus be due not so much to the loss of adrenalin as to the fact that the central nervous system is not getting sufficient lipoid from the adrenal cortex.

(b) The Pituitary undergoes little or no change either in inanition or in beriberi, except that in the latter condition certain nuclei show characteristic changes indicative of degeneration. The functions of the pituitary are apparently of such importance that they are maintained at the expense of other less necessary organs.

(c) The Thyroid shows little atrophy either in inanition or beriberi, while in both conditions the atrophy of the thymus and spleen is extreme. In cases of deficient nutrition the lymphoid tissues appear to form a reserve supply of food. Wharton in the seventeenth century recognised that atrophy of the thymus was a concomitant of exhausting or wasting disease.

3. The Genital Organs.-These undergo changes both in beriberi and inanition. Whenever the nutrition of the central nervous system is in danger the genital organs cease to function-spermatogenesis and ovulation cease. The undifferentiated cells found in the testicles of beriberic pigeons are, however, quite capable of regeneration when the necessary food-stuffs are administered. In one instance, active spermatogenesis was found in the testicle of a pigeon which six weeks previously had suffered from beriberi.

4. The changes in the kidneys, heart, and alimentary canal are very similar both in inanition and beriberi, except that in the latter there is constant evidence of nuclear degeneration. In the liver the frequent occurrence of fatty degeneration is of interest in relation to the complete disappearance of the subcutaneous fat, while the absence of mitotic figures in the liver cells is also highly characteristic of beriberi.

\section{Biochemical Experiments.}

If a satisfactory explanation of the function of vitamin $B$ is to be obtained, two conditions at least must be fulfilled:-

(1) The function must be common to all cells.

(2) The function must be of greater importance in youth than in adult life.

A function common to all cells might well be connected with the cell nucleus, while youth is essentially a period of rapid cell division.

In order to determine whether there is any quantitative relation between the nucleic acid content and the vitamin $B$ content of adult tissues, certain experiments were carried out with the organs of the ox. 
This animal was selected because the vitamin $B$ content of its organs has been worked out both by Cooper $\left(1915^{15}\right)$ and Chick and Hume $\left(1917^{16}\right)$. The minimum daily ration of the dried organ, which must be added to a diet of polished rice to prevent the onset of beriberi in a pigeon of 300 to $400 \mathrm{grms}$. weight, is as follows :-

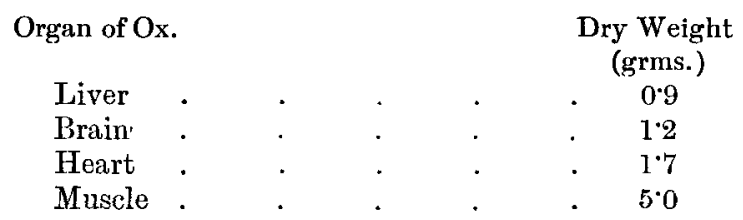

If, then, the vitamin $B$ content of ox liver be taken as 100 , the relative value of the organs is:-

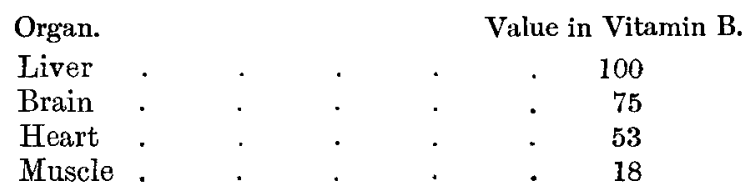

For the estimation of nucleic acid from the tissues the method recommended by Jones $\left(1915^{17}\right.$ ) was employed.

The actual weight of nucleic acid obtained from the various organs was as follows, the average of five estimations:-

\begin{tabular}{|c|c|c|c|c|}
\hline Organ. & & & & $\begin{array}{l}\text { Wt. of Nucleic Acid } \\
\text { in grms. per Kilo } \\
\text { of Organ. }\end{array}$ \\
\hline Liver & . & . & . & . $\quad 36 \%$ \\
\hline Brain & . & . & . & $20 \cdot 1$ \\
\hline Heart & . & . & . & $15^{\circ} 2$ \\
\hline Muscle & . & . & . & $5 \cdot 2$ \\
\hline
\end{tabular}

Taking the nucleic acid content of the dried liver as 100 , the following values are then obtained:-

\begin{tabular}{|c|c|c|c|}
\hline Organ of Ox. & & Value. & $\begin{array}{c}\text { Approximate } \\
\text { Water Content. }\end{array}$ \\
\hline Liver . & . & 100 & 70 \\
\hline Brain . & . & $72 \cdot 2$ & 77 \\
\hline Heart & . & 50.9 & 75 \\
\hline Muscle. & . & $17 \cdot 2$ & 75 \\
\hline
\end{tabular}

When due allowance is made for the very considerable experimental error which may occur both in the estimation of vitamin $B$ and of nucleic acid, it will be seen that there is a surprising parallelism between the values obtained for the two substances. This would suggest that in the tissues of the adult the amount of vitamin $B$ is proportional to the amount of nucleic acid. The next step was obviously to investigate the nucleic acid content of the pigeon's organs. For this purpose the brain and liver were selected. Observations were made on (1) normal pigeons; (2) pigeons with beriberi; (3) pigeons 
with beriberi nine hours after the administration of a curative dose of vitamin $B$. The values obtained are recorded in grms. per kilo of the dried organ:-

\begin{tabular}{|c|c|c|c|}
\hline 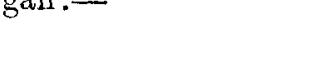 & $\begin{array}{l}\text { Normal } \\
\text { pigeon. }\end{array}$ & $\begin{array}{c}\text { Beriberic } \\
\text { pigeon. }\end{array}$ & $\begin{array}{l}\text { "Cured" } \\
\text { pigeon. }\end{array}$ \\
\hline Nucleic Acid in Liver & $29 \cdot 25$ & $19 \cdot 40$ & 2150 \\
\hline Nucleic Acid in Brain & $27 \cdot 75$ & 23.45 & $26^{\circ} 08$ \\
\hline
\end{tabular}

The diet of polished rice induced a considerable loss of nucleic acid in the liver-30.3 per cent.; while in the brain the loss was only 15.5 per cent. The administration of yeast, however, caused a considerable increase in the nucleic acid content of the brain, but only a very slight increase in that of the liver. It follows from this experiment that even in the tissues of birds suffering from beriberi there should be an appreciable amount of vitamin $B$ factor.

That such is the case is shown by the following experiment:-Five healthy hens were placed on a diet of polished rice, and in addition were given on alternate days $1 \mathrm{grm}$. of the organs of a pigeon dying of beriberi. The experiment continued for fifty days.

No. 1 received ad libitum polished rice +1 grm. of Brain of beriberic pigeon.

No. 2 received ad libitum polished rice +1 grm. of Kidney of beriberic pigeon.

No. 3 received ad libitum polished rice $+1 \mathrm{grm}$. of Muscle of beriberic pigeon.

No. 4 received ad libitum polished rice +1 grm. of Heart Muscle of beriberic pigeon.

No. 5 received ad libitum polished rice $+1 \mathrm{grm}$. of Liver of beriberic pigeon.

At the end of the experiment no birds showed symptoms of beriberic paralysis and all appeared in good health. All had increased in weight except No. 5, which had lost 2.4 per cent. of its original body-weight. Histologically there was no evidence of beriberi. This experiment shows that as long as the tissues contain nucleic acid they also contain vitamin $B$.

\section{CONCLUSIONS.}

1. The main clinical symptoms of avian beriberi are all referable to a functional paralysis of the central norvous system.

2. The histological changes produced in fowls and pigeons by a diet of polished rice are for the most part similar to those in inanition but may be differentiated by:-

(a) The evidence of nuclear degeneration;

(b) The chromatolysis in the cells of the central nervous system;

(c) The retention of lipoid in the adrenal cortex.

3. The nucleic acid content and the vitamin $B$ content of the organs of the ox are related quantitatively. 
4. As contrasted with normal birds, the livers and brains of birds with beriberi show a decrease in their nucleic acid content, more marked in the liver than in the brain

5. The admmistration of vitamin $\mathrm{B}$ to a bird suffering from beriberi is followed by :-

(a) The removal of lipoids from the adrenal cortex.

(b) An increase in the nucleic acid content of the brain.

(c) The reappearance of the Nissl granules.

(d) The disappearance of the paralytic symptoms.

6 . Vitamin $B$ is an essential factor in the synthesis of animal nucleic acid by the body.

\section{REFERENCES.}

1. Maurer . . . . Munchen. med. Woch, Munich, 1907, Bd. liv. S. 731.

2. Gibson . . . . . Philippine Journ. Sci., Manilla, 1913, vol. viii. p. 351.

3. Funk . . . . . . Zeitschr. physiol. Chem., Strassburg, 1914, Bd. lxxxv. S. 378.

4. BAELZ . . . . . . Zeitschr. f. klin. med., Berlin, 1882, Bd. iv. S. 616.

5. Scheube . . . . . . . Virch. Arch., Berlin, 1884, Bd. xcv. S. 146.

6. Vedder and Clatio . . Philippine Journ. Sci., Manilla, 1912, vol. vii. p. 204.

7. M'CARrison. . . . . . Ind. Journ. Med. Research, Calcutta, 1919, vol. vi. p. 275.

8. Prior and Jones . . . Journ. Mental Sci., London, 1920, vol. lxvi. p. 23.

9. Motт . . . . . . Brit. Med. Journ, London, 1919, vol. ii. p. 655.

10. Kossez . . . . . . Biochem. Centralbl., Leipzig, 1906, Bd. vii. S. 5.

11. Plimmer and Scott . . . Journ. Physiol., Cambridge, 1909, vol. xxxviii. p. 247.

12. Abelous and Lanclois - Arch. de Physiol., Paris, 1892, tome iv. p. 269.

13. Gourfein. . . . . . Comp. Rend. Soe. de Biol., Paris, 1895, tome cxxi. p. 311.

14. Donetti . . . . . . Comp. Rend. Soc. de Biol., Paris, 1897, tome cxxiii. p. 535.

15. Cooper . . . . . . . Journ. Hyg., Cambridge, 1913, vol. xii. p. 436.

16. Chick and Hume. . . . Proc. Roy. Soc., London, B., 1917, vol. xc. p. 44.

17. Jones . . . . . . "Nucleic Acids," London, 1915. 